\title{
PEREMPUAN LEMBAK DALAM PERGULATAN TRADISI KEAGAMAAN
}

\author{
Rodiyah \\ IAIN Bengkulu \\ ya2hufairah@gmail.com
}

\begin{abstract}
The various traditions that have implications for women's lives, including the traditions that exist in Indonesia in each region. Lembak community is one part of a tribe in Bengkulu Province, which has a unique tradition as a local power. In examining this problem, the author uses a qualitative method using the phenomenological thinking section. The author analyzes the data found in the field using bidaya hemeneutik, Cliford Great, according to the researchers photographing the Lembak community in accordance with the perceptions of the culture owner community that is the Lembak community and also the views of the community outside the culture.
\end{abstract}

Keywords: Woman, Tradition, Religious.

Abstrak. Berbagai tradisi yang ada berimplikasi terhadap kehidupan perempuan, termasuk juga dengan tradisi yang ada di Indonesia di setiap daerahnya. Masyarakat Lembak merupakan salah satu bagian dari suku yang ada di Provinsi Bengkulu, yang memiliki kekhasan tradsi sebagai kekuatan lokal. Dalam mengkaji masalah ini penulis menggunakan metode kualitatif dengan menggunakan bagian pendekatan fenomenologis Penulis menganalis data yang ditemui dilapangan dengan menggunakan hemeneutik bidaya Cliford Great, yakni peneliti memotret masyarakat Lembak sesuai dengan persepsi masyarakat pemilik budaya yaitu masyarakat Lembak dan juga pandangan masyarakat diluar budaya tersebut.

Kata Kunci: Perempuan, Tradisi, Keagamaan.

\section{Pendahuluan}

Tradisi adalah kebiasaan turun temurun, ${ }^{1}$ tradisi juga mendorong manyarakat semakin mentaati tatanan sosial tertentu. Melaui tradisi-tradisi akan memberikan motivasi dan nilai-nilai pada tingkat yang paling dalam, ${ }^{2}$ sehingga menyebabkan tradisi menjadi suatu yang sulit dirubah karena sudah 1994), 756.

${ }^{1}$ Pius A Partanto dan M. Dahlan Al Barry, Kamus Sosial Populer, (Surabaya : Arkola, 122

${ }^{2}$ M. Darori Amin (ed), Islam dan Kebudayaan Jawa (Yogyakarta: Gama Media, 2002), 
menyatu dalam kehidupan masyarakat. Sedangkan tradisi keagamaan adalah suatu kebiasaan yang secara turun temurun yang latarbelakangi atau yang dipengaruhi oleh agama, ${ }^{3}$ Tradisi yang ada di setiap pelosok Negeri menjadi kekhasan sekaligus sebagai kekuatan yang akan mendukung kearifan lokal disetiap daerah.

Diantara keragaman tradisi tersebut adalah tradisi masyarakat Suku Lembak yang bermukim pada beberapa Desa dan Kecamatan yang ada di Provinsi Bengkulu, salah satunya berada di Desa Rena Semanek Kecamatan Karang Tinggi Kabupaten Bengkulu Tengah, yang merupakan bagian dari Lembak Delapan Nibung Laut yang mendiami Desa Rena Lebar, Rena Semanek dan juga Padang Tambak. Adapun bentuk-bentuk tradisi keagamaan masyarakat Lembak di Desa Rena Semanek diantaranya adalah: Tradis kenuri, cerita mulud, mace kayat, besulub, reraye, bedikir dan bebagi juada. ${ }^{4}$

Dalam berbagai kegiatan tradisi keagamaan yang di masyarakat Lembak Renah Semanek perempuan memiliki peran serta dan kontribusi yang tidak bisa di pandang sebelah mata, karena tugas dan tanggung jawab yang cukup strategis dipercayakan kepada perempuan jika tidak dilaksanakan secara sungguhsungguh maka akan menjadi hambatan terlaksananya ritual tradisi keagamaan masyarakat Lembak.

Patisipasi perempuan dalam kegiatan tradisi yang sigtifikan tersebut terkadang tidak sebanding dengan penghargaan dan kontribusinya dalam kehidupan perempuan, baik kehidupan pribadi, berkeluarga maupun dalam kehidupan bermasyarakat.

\section{Pembahasan}

Tulisan ini menggambarkan tentang posisi perempuan dalam kegiatan tradisi masyarakat Lembak, disatu sisi perempuan ikut berpartisipasi aktif untuk terlaksananya tradisi keagamaan namun disisi lain perempuan semakin diberi kenyamanan diruang domestik dan dibatasi partisipasi di ruang publik. Adapun metode yang penulis gunakan adalah metode kualitatif dengan pendekatan fenomenologis dan dianalisis dengan hermeneutik budaya atau penafsiran budaya merupakan usaha untuk memahami tindakan sebuah kelompok layaknya seseorang yang menguji sebuah naskah tertulis dan berusaha untuk mencari tahu maksudnya.

Clifford Greetz merupakan seorang penafsir budaya atau etnograf yang besar, Greetz menggambarkan penafsiran budaya sebagai deskripsi padat (thick descrition) dimana penafsir menggambarkan kegiatan-kegiatan budaya "dari sudut pandang penduduk asli". Tingkat penafsiran ini berbeda dengan deskripsi tipis

${ }^{3}$ Galuh Subeekti, Tradisi Keagamaan Masyarakat Etnis Banjar di Tulungagung, (Skripsi: UIN Sunan Kalijaga, 2009), 11

4. Rindom Harahap, Yuhaswita, Rodiyah, Realitas Perempuan dalam Tradisi Masyarakat Lembak, Hasil Penelitian, 2017, LPPM IAIN Bengkulu 
(thin description), dimana orang-orang hanya menggambarkan pola prilaku dengan sedikit pemahaman tentang apa maksudnya bagi para pelaku itu sendiri. ${ }^{5}$

Dalam penafsiran budaya, lingkaran hermueneutik ini merupakan gerakan dari konsep pengalaman dekat ke konsep pengalaman jauh. Konsep pengalaman dekat (experience-near concept) adalah konsep yang memiliki makna bagi anggota sebuah budaya dan konsep pengalaman jauh (experience-distant concept) memiliki makna bagi orang di luar budaya tersebut. Penafsir budaya sebenarnya menerjemahkan keduanya sehingga pengamat dari luar dapat memahami perasaan dan pemaknaan anggota sebuah budaya dalam sebuah situasi. Selanjutnya, proses penafsiran adalah sebuah gerakan maju mundur dalam sebuah lingkaran antara apa yang terjadi dari luar ke apa yang orang dalam artikan sebagai sebuah kejadian. ${ }^{6}$

Oleh karena itu dalam tulisan ini penulis akan menggunakan teori interaksionisme simbolik untuk memahami budaya masyarakat Lembak dengan melihat realitas prilaku manusia. Sedangkan teori kelompok terpendam (muted grouf theory) penulis gunakan untuk melihat perempuan dalam tradisi keagamaan masyarakat Lembak. Adapun hermeneutika budaya atau penafsiran budaya sebagai alat yang penulis gunakan untuk memaknai realitas perempuan dalam tradisi keagamaan dalam pandangan masyarakat Lembak itu sendiri, serta bagaimana orang luar budaya tersebut memberi makna terhadap budaya tersebut.

Sebagaimana teori kelompok terpendam (muted grouf theory) ketika mengkaji realitas perempuan dalam kegiatan tradisi keagamaan masyarakat Lembak. Walaupun perempuan memiliki peran strategis dalam berbagai kegiatan tersebut, akan tetapi perempuan tetap tersembunyi di area domestik dan tidak sebebas dan seekspresif laki-laki ketika berada di are publik dan itu juga didukung dengan tradisi yang ada di masyarakat Lembak Desa Renah Semanek yang lebih menekankan peran domestik perempuan dan cenderung membatasi kehadiran perempuan di area publik.

Sedangkan teori Models of Reality dan Models for Reality Clifford Greertz, teori ini didasrkan pada asumsi bahwa agama adalah sistem sistem simbol di mana simbol-simbol tersebut bersatu membentuk pola-pola budaya yang pada gilirannya membentuk model. Models of reality dimaknai sebagai adaptasi terhadap budaya-budaya atau realitas. Proses ini kemudian berlanjut dengan models for reality, dimana agama memberikan konsep atau doktrin untuk realitas.

\footnotetext{
${ }^{5}$ Clifford Greetz, The Intrpretation Of Cultures (New Yoork: Basic, 1973).

${ }^{6}$ Stephen W.Littlejohn.Karen A. Foss, Theories of Human Communication Terj. Teori Komunikasi,(Jakart: Selemba Humanika, 2009), 456

7 Clifford Greetz, The Intrpretation Of Cultures, Selected Essays (New Yoork: Basic Books, 1973), 93
} 
Seperti yang penulis temui bahwa perempuan dalam tradisi kenuri pada masyarakat Lembak, yang diundang pada kegiatan kenuri ini biasanya hanyalah kaum bapak atau hanya laki-laki, perempuan tidak diundang dalam kegitan kenuri. Perempuan yang datang kerumah yang sedang melaksanakan kenuri hanya keluarga dekat dan tetangga dekat saja yang bertujuan untuk membantu berbagai proses kegiatan kenuri seperti memasak nasi dan sayur, nyendok gulai ( memasukkan sayur ke dalam piring) dan yang terakhir membantu mencuci piring. ${ }^{8}$

Demikin juga dalam tradisi cerita mulud setelah menyiapkan semua keperluan tradisi cerita mulud seperti dulang yang didalamnya terdiri dari juada, nasi beserta lauk pauknya oleh kaum ibu atau perempuan, namun mereka biasanya tidak ikut datang ke Masjid karena yang hadir di Masjid itu hanyalah laki-laki mulai dari anak-anak sampai laki-laki dewasa.

Setelah penulis menanyakan alasan ketidakhadiran perempuan pada acara kenuri maupun acara cerita mulud, mereka mengatakan bahwa itu adalah tradisi atau kebiasaan yang telah mereka anut sejak dulu bahwa ketika diadakan kenuri hanya mengundang kaum laki-laki saja, sehingga perempuan tidak terbiasa berada di tempat kegiatan kenuri akan dilaksanakan, berbeda dengan laki-laki memang diperbolehkan dan tidak dipermasalahkan.

Namun hal tersebut tidak membuat kaum perempuan merasa diperlakukan berbeda, karena menurut mereka semua sudah memiliki peran dan tugas masing-masing dalam berbagai kegiatan tradisi keagamaan Lembak yang ada di Desa Rena Semanek Kecamatan Karang Tinggi Kabupaten Bengkulu Tengah. Selain itu kaum perempuan beranggapan bahwa ketentuan itu adalah tradisi yang harus ditaati oleh setiap anggota masyarakat walaupun itu bukan ketentuan agama tapi mentaati tradisi tersebut secara tidak langsung menurut mereka adalah bagian dari pelaksanaan nilai-nilai ajaran Islama yang ada di dalam kegiatan tradisi keagamaan tersebut. ${ }^{10}$

Sedangkan dalam persepsi masyarakat dari luar budaya tersebut menganggap bahwa hal tersebut bersifat tidak adil dan diskriminasi terhadap perempuan. Hal itu dikarenakan perempuan terus disibukkan dengan berbagai aktivitas persiapan kegiatan tradisi keagamaan, namun ketika pada kegiatan formal dan resminnya perempuan tidak diikutsretakan. Fenomena tersebut seolah semakin memberi kenyamanan kepada perempuan diarea domestik dan membatasi aktivitas perempuan diarea publik.

\footnotetext{
${ }^{8}$ Rindom Harahap, Yuhaswita, Rodiyah, Realitas Perempuan dalam Tradisi Masyarakat Lembak, Hasil Penelitian, 2017, LPPM IAIN Bengku

${ }^{9}$ Cerita Mulud dalah kegiatan tradisi masyarakat Lembak Renah Semanek dalam memperingati kelahiran Nabi Muhammad SAW.

${ }^{10}$ Rindom Harahap, Yuhaswita, Rodiyah, Realitas Perempuan dalam Tradisi Masyarakat Lembak, Hasil Penelitian, 2017, LPPM IAIN Bengkulu
} 
Selanjutnya teori kelompok terpendam (muted grouf theory) yang merujuk pada hasil penelitian antropolog Edwin Erdener dan Shirley Erdener dikutip oleh Sthephen W. Littlejhon dan Karen A. Foss hasil Edwin dan Shirley mengamati bahwa antropolog cenderung menggolongkan sebuah budaya dalam istilah maskulin, dan bahasa asli sebuah kebudayaan memiliki unsur bias yang melekat pada pria, bahwa pria menciptakan pemaknaan terhadap suatu kelompok dan suara feminim ditekan atau dihilangkan sehingga perempuan tidak berdaya dalam mengekspresikan diri mereka sendiri dalam gaya bahasa pria. Selanjutnya Shirley Erdener menambahkan dengan pembungkaman perempuan memiliki manifestasi dan bukti pada wacana publik. Seperti perempuan kurang merasa nyaman dan kurang ekspresif dimuka umum dari pada pria serta mereka kurang bisa nyaman di muka umum dari pada dalam situasi yang lebih pribadi. Sebagai akibatnya perempuan mengawasi komunikasi mereka sendiri lebih intensif dari pada yang pria lakukan. ${ }^{11}$

Oleh karena itu, dalam kegiatan tradisi keagamaan di masyarakat Lembak Desa Renah Semanek perempuan tidak begitu nyaman berada di ruang publik tapi lebih nyaman di ruang publik, hal tersebut dikarenakan secara tidak langsung perempuan sudah dikondisikan untuk sibuk di area domestik dan terbatas di area publik. Sebagaimana yang dikemukakan oleh Shirley Erdener menambahkan dengan pembungkaman perempuan memiliki manifestasi dan bukti pada wacana publik. Seperti perempuan kurang merasa nyaman dan kurang ekspresif dimuka umum dari pada pria serta mereka kurang bisa nyaman di muka umum dari pada dalam situasi yang lebih pribadi.

Secara historis, perempuan telah berpartisipasi di dalam ruang publik dan ikut mewarnai kontestasi politik di dalam sejarah peradaban Islam. Peran publik ini seringkali diabaikan atau dihilangkan oleh mainstream intelektual dan masyarakat Islam, karena adanya kepentingan politis tertentu untuk menjaga kelangsungan status quo atau dominasi laki-laki. Seperti dinyatakan oleh Husein Muhammad yang dikutip oleh Eliya Munfaridah sejarah pemikiran Islam yang sangat panjang ini, banyak menyembunyikan sisi lain pemikiran Islam yang tidak mainstream. Padahal, banyak sekali pemikiran dan opini hukum Islam yang maju, namun tidak populer dan tidak muncul ke permukaan. Hal ini terjadi karena Islam yang kita warisi ini adalah Islam politik; selalu ada kekuasaan-kekuasaan politik yang memihak pandanganpandangan tertentu dan melenyapkan pandangan lainnya dan baginya, pandangan-pandangan utama yang tampil dan didukung penguasa dinastidinasti Islam yang berumur panjang, juga jelas-jelas memperlihatkan bentuk wacana yang patriarkhis. ${ }^{12}$

${ }^{11}$ Stephen W.Littlejohn.Karen A. Foss, Theories of Human Communication Terj. Teori Komunikasi, (Jakart: Selemba Humanika, 2009), h. 170.

12 Elya Munfaridah, "Perempuan dalam Tafsir Fatima Mernissi”, Jurnal Maghza, Vol 1 No 2 Juli-Desember 2016. 
Bias politis dalam sejarah seperti dinyatakan oleh Husen Muhammad, juga dirasakan oleh Fatima Mernissi yang menurutnya telah mengeliminir atau bahkan memelintir peran aktif perempuan dalam ruang publik. Kekuatan-kekuatan tertentu yang menghilangkan peran aktif perempuan dalam sejarah, telah mendiskriminasi perempuan melalui pembentukan citra-citra negatif dan pasif tentang perempuan.

Gambaran tersebut menunjukkan bahwa secara historis perjuangan perempuan untuk menuntut hak-haknya sudah dilakukan dari masa dahulu, walupun budaya patriarkhis menjadi hambatan besar bagi kaum perempuan untuk mendapatkan perlakuan setara dalam kehidupan masyarakat, tapi tidak bisa dipungkiri bahwa perlakuan berbeda terhadap perempuan dalam kehidupan masyarakat masih bisa dirasakan sampai saat ini.

Tradisi masyarakat yang lebih mempposisikan laki-laki lebih tinggi dibandingkan dengan perempuan, membuat perempuan sudah terbiasa dan mengangap hal tersebut sudah seharusnya perempuan terima, kondisi ini juga menjadi terus menerus terjadi di dalam kehidupan masyarakat. Selanjutnya anggapan bahwa tugas demostik adalah tanggung jawab perempuan sedangkan area publik adalah ranahnya kaum laki-laki, sehingga perempuan membatasi aktivitas di ruang publik dan lebih fokus dalam kegiatan di dalam rumah seperti merapikan rumah, memasak, mengash anak dan lain sebagainya.

Pergulatan perempuan dengan teradisi ditempat dia tinggal dan bersosialisasi terus terjadi, walaupun perempuan tidak merasa bahwa mereka diperlakukan berbeda. Hal itu dikarenakan kaum perempuan sudah terbiasa dalam lingkungan yang patriarkhi, yang memang memposisikan antara laki-laki dan perempuan secara berbeda, sehingga perempuan merasa bahwa kehidupan sosial antara laki-laki dan perempuan memang seperti yang mereka jalani seperti biasanya.

Lebih dari itu perempuan beranggapan bahwa ajaran agama juga menganjurkan hal demikian, agar perempun lebih fokus di rumah dan membatasi diri dalam aktivitas publik. Sedangkan terkait dengan perlakuan berbeda antara kaum laki-laki dengan kaum perempuan dalam kehidupan sosial sudah di anggap wajar karena laki-laki adalah imam dan di anggap lebih utama dibandingkan dengan kaum perempuan.

${ }^{13}$ Fatima Mernissi, "Perempuan dalam Sejarah Muslim: Perspektif Tradisional dan Strategi Baru", dalam Fatima Mernissi dan Riffat Hassan, Setara di Hadapan Allah (Yogyakarta: LSSPA, 2000), 176. 


\section{Penutup}

Pergulatan perempuan dalam tradisi pada dasarnya terus terjadi, disatu sisi perempuan memiliki peran yang signifikan untuk melestarikan tradisi masyarakat setempat, namun disisi lain perempuan mengalami diskriminasi atau perlakuan yang berbeda dengan kaum laki-laki. Hal itu dikarenakan tradisi yang ada semakin mendukung dan menguatkan bahwa area domestik lebih utama bagi perempuan sedangkan secara langsung ataupun tidak langsung tradisi masyarakat Lembak Renah Semanek membatasi keterlibatan perempuan di ruang publik studi ini memerlukan kajian lebih lanjut mengenai dampak pembatasan tersebut bagi perempuan suku Lembak yang memegang erat tradisi masyarakat Renah Semanek.

\section{Daftar Pustaka}

Amin M. Darori. (ed). 2002. Islam dan Kebudayaan Jawa. Yogyakarta: Gama Media.

Greetz, Clifford. 1973. The Intrpretation Of Cultures. New Yoork: Basic

Harahap, Rindom, Yuhaswita, Rodiyah. 2017. Realitas Perempuan dalam Tradisi Masyarakat Lembak, Hasil Penelitian, LPPM IAIN Bengkulu

.Littlejohn. Stephen W Karen A. Foss. 2009. Theories of Human Communication Terj. Teori Komunikasi,(Jakart: Selemba Humanika.

Mernissi, Fatima. 2000. "Perempuan dalam sejarah Muslim: Perspektif Tradisional dan Strategi Baru", dalam Fatima Mernissi dan Riffat Hassan, Setara di Hadapan Allah. Yogyakarta: LSSPA

Munfaridah, Elya. 2016. "Perempuan dalam Tafsir Fatima Mernissi", Jurnal Maghza, Vol 1 No 2 Juli-Desember.

Partanto, Pius A dan M. Dahlan Al Barry. 1994. Kamus Sosial Populer, Surabaya : Arkola.

Subeekti, Galuh. 2009. Tradisi Keagamaan Masyarakat Etnis Banjar di Tulungagung. Skripsi: UIN Sunan Kalijaga 